\title{
HANGING CASES IN AMCH MORTUARY, DIBRUGARH, ASSAM- TWO YEARS STUDY
}

\author{
Tarun Kumar Das¹, Nayan Mani Pathak², Rupak Kumar Gogoi ${ }^{3}$ \\ ${ }^{1}$ Associate Professor, Department of Forensic Medicine, Assam Medical College and Hospital, Dibrugarh, Assam. \\ ${ }^{2}$ Assistant Professor, Department of Forensic Medicine, Assam Medical College and Hospital, Dibrugarh, Assam. \\ 3Professor, Department of Forensic Medicine, Assam Medical College and Hospital, Dibrugarh, Assam.
}

\section{BACKGROUND}

Hanging is one of the commonest method of suicide in India. Increasing stress and strain of modern days becomes a common cause of people taking their own life to overcome the miserable situation they face. Though hanging is almost always suicidal, there are situations where it is found to be homicidal or it looks like suicidal hanging. Detailed post-mortem examination and also crime scene investigation helps to understand the manner of death. This study was conducted to see hanging related death in depth so that it helps to opine the manner of death as well as understand the circumstances of death which will definitely help to design a method to decease the suicidal rate.
\end{abstract}

ABSTRACT

\section{MATERIAL AND METHODS}

The present study was undertaken for two years during January 2014 to December 2015 at the mortuary of Assam Medical College \& Hospital, Dibrugarh, Assam to know various autopsy findings and analysis of sociodemographic data. All hanging death cases which came for post-mortem examination were included in the study. The data was obtained in predesigned proforma and analysed accordingly.

Study Design- It is an observational descriptive study.

\section{RESULTS}

Out of 2811 total number of autopsies done during the said period, 169 (6\%) cases died due to hanging. Incidences of hanging were found to be more in males; a total of 122 (72\%). Study showed higher number of incidences in married group and of lower socioeconomic status people. The deaths were more in the age group of 21-30 years (33.13\%). In maximum number of cases, victims used soft material as ligature.

\section{CONCLUSION}

Suicide rate is seen more in the younger generation which may reflect the fact that these people may be at greater stress due to poverty, illiteracy, marital disharmony, stress at work place and also dowry related matters. All the cases showed typical findings of ante-mortem suicidal hanging like obliquity and non-continuity of the ligature mark.

\section{KEYWORDS}

Hanging, Suicide, Ligature, Hyoid Bone, Saliva Mark.

HOW TO CITE THIS ARTICLE: Das TK, Pathak NM, Gogoi RK, et al. Hanging cases in AMCH mortuary, Dibrugarh, Assam- Two years study. J. Evolution Med. Dent. Sci. 2017;6(51):3882-3884, DOI: 10.14260/Jemds/2017/839

\begin{tabular}{ll}
\hline BACKGROUND & and analyse the socio-demographic pattern as well as age, sex \\
Hanging is defined as a violent form of asphyxia where a & factor, external and internal findings at autopsy, \\
person is suspended by a ligature around his neck and the & $\begin{array}{l}\text { circumstantial evidences which invariably help to understand } \\
\text { the manner and circumstances of death. }\end{array}$
\end{tabular}
deaths are generally taken as suicidal unless proved otherwise. Hanging is considered to be one of the commonest method of suicide all over the world. The increasing stress and strain of modern day-to-day life along with poverty makes people to commit suicide. As our community is male dominated, he is exposed to the majority of stress alone, more than the female which is reflected in the fact that suicide rate by hanging is more in males. Present study tries to elaborate

Financial or Other, Competing Interest: None.

Submission 05-05-2017, Peer Review 14-06-2017,

Acceptance 19-06-2017, Published 24-06-2017.

Corresponding Author:

Dr. Tarun Kumar Das,

Associate Professor,

Department of Forensic Medicine,

Assam Medical College and Hospital,

Dibrugarh, Assam.

E-mail: drtkdas52@gmail.com

DOI: $10.14260 /$ jemds $/ 2017 / 839$

\section{MATERIAL AND METHODS}

The present study was conducted at AMCH Mortuary, Department of Forensic Medicine, Dibrugarh, Assam, from January 2014 to December 2015, a period of two years. All cases of death due to hanging brought by police from different police stations to our department for medicolegal autopsy were included in the present study.

\section{The Various Data were collected from-}

1. Documents supplied by the investigating officers namely inquest report, forwarding letter, dead body challan, photograph, ligature materials, etc.

2. Interviewing the escorting police personnel, family members, relatives, friends and neighbours of the deceased.

3. Post-mortem examination. 
The different data were obtained in predesigned proforma and thoroughly compiled, tabulated and analysed.

The statistical analysis was discussed under various results and observations. The discussion was made and compared with similar works already done by other authors and various studies.

\section{RESULTS}

Out of 2811 total number of autopsies done during the said period, $169(6 \%)$ cases died due to hanging. Incidences of hanging were found to be more in males; a total 122 (72\%) cases as compared to females which were 47 (28\%) cases. [Figure 1].

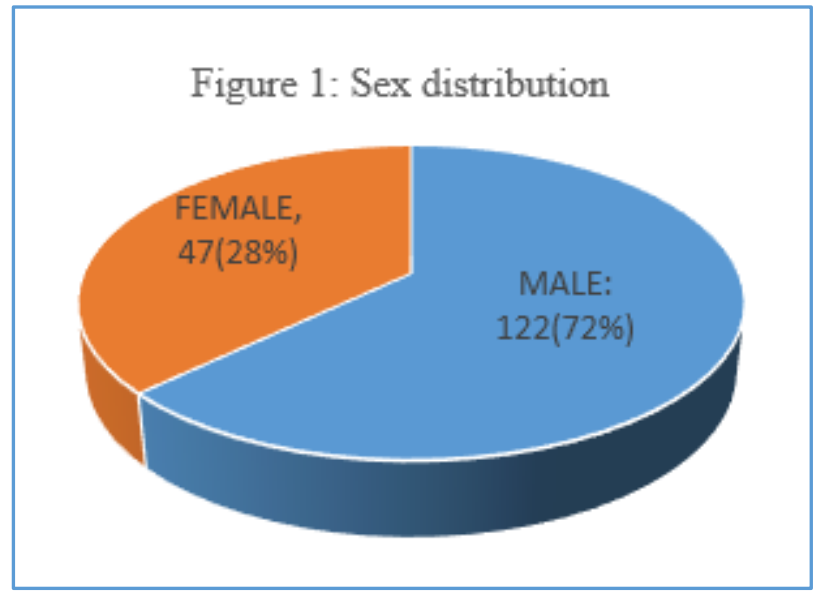

The deaths were more in the age group of 21-30 years at $56(33.13 \%)$ cases followed by $34(20.11 \%)$ cases in the age group of 11-20 years.

\begin{tabular}{|c|c|c|c|c|}
\hline Age (Years) & Male & Female & Total & \% \\
\hline $0-10$ & 0 & 0 & 0 & 0 \\
\hline $11-20$ & 14 & 20 & 34 & 20.11 \\
\hline $21-30$ & 43 & 13 & 56 & 33.13 \\
\hline $31-40$ & 24 & 8 & 32 & 18.93 \\
\hline $41-50$ & 21 & 4 & 25 & 14.79 \\
\hline $51-60$ & 9 & 2 & 11 & 6.5 \\
\hline $61-70$ & 4 & 0 & 4 & 2.36 \\
\hline $71-80$ & 6 & 0 & 6 & 3.55 \\
\hline $81-90$ & 1 & 0 & 1 & 0.59 \\
\hline \multicolumn{6}{|r}{ Table 1. Age Wise Distribution of Cases } \\
\hline
\end{tabular}

Maximum victims were found to be married, 110 (65\%) cases [Figure 2].

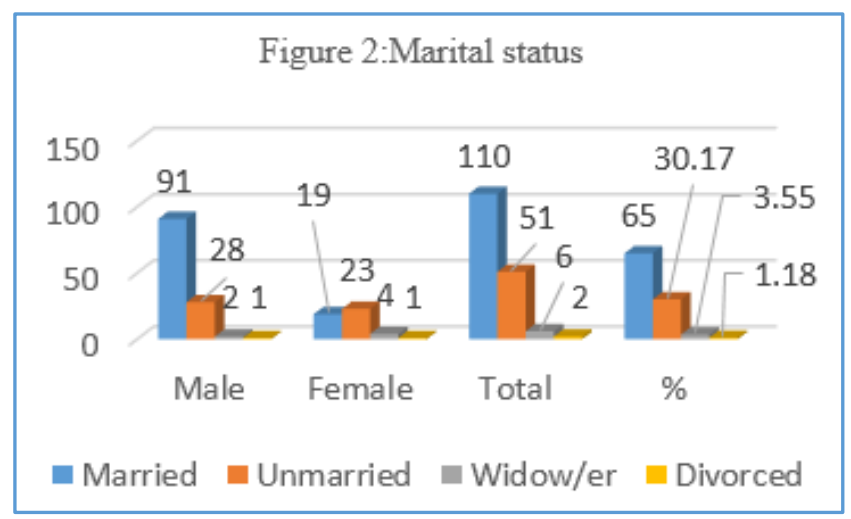

Figure 2. Marital Status
Our study showed that commonest victims are from lower socioeconomic status group, 125 (73.89\%) cases. Surprisingly, not a single incidence was found in the higher socioeconomic group [Table 2].

\begin{tabular}{|c|c|c|c|c|}
\hline $\begin{array}{c}\text { Socioeconomic } \\
\text { Status }\end{array}$ & Male & Female & Total & $\mathbf{\%}$ \\
\hline Upper class & 0 & 0 & 0 & 0 \\
\hline Middle Class & 34 & 7 & 41 & 24.26 \\
\hline Lower class & 85 & 40 & 125 & 73.89 \\
\hline Not known & 3 & 0 & 3 & 1.77 \\
\hline \multicolumn{7}{|l}{ Table 2. Socioeconomic Status } \\
\hline
\end{tabular}

In the analysis of educational status of victims, it was found that most of the victims were illiterate i.e. 71 (40.01\%) cases. Present study shows majority of incidences occurred in closed spaces, 118 (69.82\%) cases. Mark of saliva seen in 114 $(67.49 \%)$ cases. In our study, on the basis of position of the knot of the ligature mark, it was found that number of atypical hanging was more, $109(64.5 \%)$ cases whereas typical hanging was seen in 60 (35.5\%) cases [Figure 3].

Figure 3: Type of hanging on basis of position of the knot

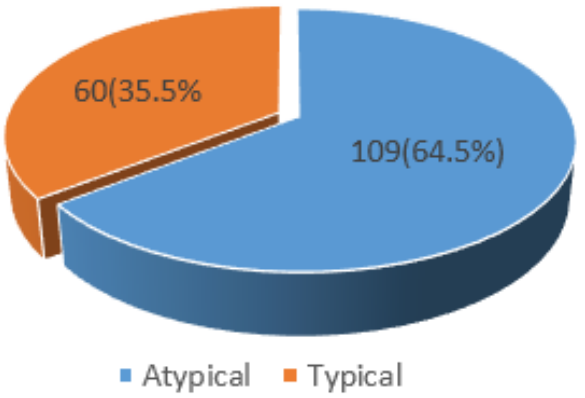

In maximum number of cases (97 cases, 57\%), victims used soft material as ligature, such as Gamocha (13.83\%), scarf/Dopatta (14.2\%), Dhoti (7.46\%), Saree (9.87\%), Chador (5.91\%) and Bed sheet (5.73\%). In all the cases in the present study, the ligature mark was found to be oblique and noncontinuous. Level of ligature found above thyroid cartilage in $123(72.78 \%)$ cases. In $9(5.32 \%)$ cases fracture of neck bone seen where 8 number of cases had fracture of hyoid bone alone and in 1 case there was fracture of both hyoid and thyroid cartilage [Table 3].

\begin{tabular}{|c|c|c|}
\hline Bones & Number of Case & $\mathbf{\%}$ \\
\hline Hyoid alone & 8 & 4.73 \\
\hline Thyroid cartilage alone & 0 & 0 \\
\hline Hyoid + Thyroid cartilage & 1 & 0.59 \\
\hline \multicolumn{2}{|c|}{ Table 3. Fracture of Neck Bones }
\end{tabular}

\section{DISCUSSION}

It is found that in our study $6 \%$ cases died from hanging. Higher incidences of hanging amongst male is found worldwide. Present study showed male preponderance $(72 \%)$ whereas female victims were only $28 \%$. A study by Kanchan T, Menezes RG et al and a study done by Sharma BR, Harish $\mathrm{D}$ et al found male and female ratio of $2: 1$ which is similar to our study.1,2 However, study done by Nikolic $S$, Mictic $J$ et al found much higher ratio of male to female of $3.17: 1 .^{3}$ In the present study, higher incidences in the age 
group of $21-30$ years (33.13\%) is found which is similar to other authors' studies like Sharma BR, Harish D et al (27\%), 2 Kumar N, Sahoo N Panda DB (maximum number of cases belonged to the age group of 21-30 years) ${ }^{5}$, Naik SSK, Patil DY in their study found out of 257 hanging cases, 136 fell under the age group of 21-30 years. ${ }^{6}$ Maximum number of incidences were found in the married group (65\%)and also from the lower socioeconomic status (73.89\%). Udhayabanu R, Senti Toshi, Bhaskar R. in a study found $76.77 \%$ victims to be married. ${ }^{7}$ Samanta AK and Nayak SR observed that hanging is increasingly being adopted by people from poor socioeconomic status with $82.5 \%$ cases, in their study. ${ }^{8}$ Madini OMA, Kharoshah MA, Zaki MK in their study found that $75 \%$ of the deceased were male labourers, $11.27 \%$ cases were female house maids and $9.77 \%$ were unemployed. ${ }^{9}$ The present study when compared to other studies, it was found that soft ligature material is most commonly used (57\%) and type of hanging found to be atypical (64.5\%). Sharma BR, Harish D, Singh VP in their study found $80 \%$ cases to be atypical hanging. ${ }^{2}$ Naik SKK, Patil DY found in their study that $7.39 \%$ cases were typical hanging and rest were atypical hanging and they also found that soft ligature material was used in 54.74\% cases and hard ligature material used in $45.26 \%$ cases. $^{6}$ Meera TH, Singh MBK observed in their study that $57.14 \%$ of cases used cloth as a ligature material and $42.86 \%$ cases used rope as ligature material. ${ }^{10}$ In our study, ligature mark found above the level of thyroid (72.78\%). Sharma BR, Harish D, Singh VP in their study showed that ligature mark was obliquely placed in $98 \%$ cases and in $84.62 \%$ cases the mark was above the laryngeal prominence. ${ }^{2}$ Naik SKK, Patil DY in their study found that out of 257 cases of hanging, 159 cases had ligature mark above the level of laryngeal prominence, in 53 cases was on laryngeal prominence and in 12 cases was below the level of laryngeal prominence. ${ }^{6}$ Dribbling mark of saliva found in $67.45 \%$ cases. Kumar Ashok Samanta and Nayak SR in a study noticed dribbling mark of saliva in $25.71 \%$ cases. ${ }^{8}$ We found only few cases of fracture of hyoid bone alone $(4.73 \%)$ and this tallies with other authors. Meera TH, Singh MBK and Naik SKK, Patil DY in their study found that fracture of hyoid bones and thyroid cartilage were detected in only $3.57 \%$ cases and 2.38\% cases respectively. ${ }^{6,10}$ Clement R, Guay Jean Pierre, Sauvageau Anny in a study of suicidal hanging that out of total 206 cases, fracture of hyoid bone was found in 13 cases ( $6.31 \%$ ) of which 3 were isolated hyoid fractures and 10 cases were associated with thyroid cartilage fracture.11Majority number of cases showed visceral congestion in internal examination which is a typical sign of asphyxia death.

\section{CONCLUSION}

Death due to hanging found to be almost always suicidal in nature. Suicide rate is seen more in the younger generation which may reflect the fact that these people may be at greater stress due to poverty, illiteracy, marital disharmony, stress at work place and also dowry related matters. Hanging is commonly selected as a method of committing suicide as it is considered to be a painless way of death and also no other sophisticated tools are necessary. All the cases showed oblique and non-continuous ligature mark which is a typical finding of ante-mortem hanging. Also in majority cases, we have seen dribbling of saliva mark which is regarded as a confirmatory sign of ante-mortem hanging. People generally prefer closed space for the act so that no one can interfere during the act or maybe for fear of failure of their attempt. Identification and proper counselling of persons who are at risk of committing suicide may help to prevent and lower the rate of suicide as well as hanging.

\section{REFERENCES}

[1] Kanchan T, Menezes RG. Suicidal hanging in Manipal, South India-victim profile and gender differences. J Forensic \& Legal Medicine 2008;15(8):493-6.

[2] Sharma BR, Harish D, Singh VP, et al. Ligature mark on neck: how informative. Journal of Indian Academy of Forensic Medicine 2005;27(1):10-5.

[3] Nikolic S, Micic J, Atanasijevic T, et al. Analysis of neck injuries in hanging. American journal of forensic medicine and pathology 2003;24(2):179-82.

[4] Sharma BR, Harish D, Sharma S, et al. Injuries to neck structures in death due to constriction of neck, with a special reference to hanging. Journal of forensic and legal medicine 2008;15(5):298-305.

[5] Kumar N, Sahoo N, Panda BB. Demographic profile of hanging cases autopsied in RIMS, Ranchi. Global journal of Research analysis 2006;5(3):119-21.

[6] Naik SKK, Patil DY. Fracture of hyoid bone in case of asphyxia death resulting from constricting force round the neck. Journal of Indian Academy of Forensic Medicine 2005;27(3):149-53.

[7] Udhayabanu R, Toshi S, Baskar R. Study of hanging cases in Pondicherry region. Journal of Dental and Medical Science 2015;14(7):41-4.

[8] Samanta AK, Nayak SR. Newer trends in hanging death. Journal of Indian Academy of Forensic Medicine 2012;34(1):37-9.

[9] Madini OMA, Kharoshah MA, Zaki MK. Hanging deaths in Dammam, kingdom of Saudi Arabia. Journal of Forensic \& Legal Medicine 2010;17(5):265-8.

[10] Meera TH, Singh MBK. Pattern of neck findings in suicidal hanging a study in Manipur. Journal of Indian Academy of Forensic Medicine 2011;33(4):352-4.

[11] Clement R, Pierre GJ, Anny S. Fracture of the neck structures in suicidal hanging: a prospective study on contributing variables. Forensic Science International 2011;207(1-3):122-6. 